\title{
Association of Socio-demographic Attributes with Mothers Knowledge regarding Childhood Diarrhea
}

\author{
Jesmin Akter ${ }^{1, *}$, Kazi Rumana Ahmed ${ }^{2}$, Hasina Akhter Chowdhury ${ }^{3}$, Sharmin Hossain ${ }^{2}$ and \\ Begum Rowshan Ara ${ }^{1}$
}

\author{
${ }^{1}$ Department of Reproductive and Child Health, Faculty of Public Health, Bangladesh University of Health \\ Sciences (BUHS), 125/1, Darus Salam, Mirpur, Dhaka-1216, Bangladesh \\ ${ }^{2}$ Department of Health Promotion and Health Education, Faculty of Public Health, Bangladesh University of \\ Health Sciences (BUHS), 125/1, Darus Salam, Mirpur, Dhaka-1216, Bangladesh \\ ${ }^{3}$ Department of Biostatistics, Faculty of Allied Health Sciences, Bangladesh University of Health Sciences \\ (BUHS), 125/1, Darus Salam, Mirpur, Dhaka-1216, Bangladesh
}

\begin{abstract}
Background: Childhood diarrheal diseases have a major impact on morbidity and mortality and these deaths are due to dehydration and mismanagement or delayed management of the disease. The mothers' knowledge in management of diarrhea is likely related to its mortality and morbidity. The study aimed to determine the association between socio demographic attributes and mother's knowledge on childhood diarrhea.

Materials and Methods: In this cross sectional analytic study, 170 mothers who had at least one child aged below five years old were selected purposively from the out-patient department of ICDDR,B, Dhaka. Data were collected using a structured questionnaire by face to face interview. The level of knowledge was categorized as poor, average and good. Univariate and bivariate analysis were done with level of significance $\mathrm{P}<0.05$.

Results: The mean age of the respondents was $27(\mathrm{SD}= \pm 5.6)$ years. Among them $46.5 \%$ were educated up to primary level and $47 \%$ had average monthly income between 5001 and 10000 taka. In the case of accessibility to mass media, $20 \%$ were found who never watch TV, $75.9 \%$ participants were found who never listen to radio, and $87.6 \%$ were found who never read newspaper. Despite the level of average knowledge was $59.5 \%$ but the proportion of the level of good knowledge was $17 \%$ among the respondents. Socio-demographic characteristics such as age, education and income $(p<0.001)$ were significantly associated with mothers knowledge.
\end{abstract}

Conclusion: The mothers had inadequate knowledge about diarrhea and their socio-demographic parameters are strongly associated with mother's knowledge regarding diarrhea.

Keywords: Mother's Knowledge, Diarrhea, Children, Socio-demographic attributes.

\section{INTRODUCTION}

Diarrheal diseases is one of the two major killer diseases in children aged less than five years in the developing world and are major causes of morbidity and mortality in children particularly in this region [1-4]. Diarrheal diseases in children under five years age are perhaps the most common human ailment that is the source of discomfort, misery and loss of time to their parents and burden to health system as compared to their older siblings in which the course of disease is mild.

Diarrhea is usually caused by one of the number of food borne or water borne pathogens. Improvements in environmental factors such as supply of adequate and clean drinking water, improvements in sanitation facilities, and personal hygiene thus can play an important role in reducing the incidence of diarrhoea. Deaths in diarrheal cases are largely attributable to it

${ }^{*}$ Address correspondence to this author at the Department of Reproductive and Child Health, Faculty of Public Health, Bangladesh University of Health Sciences (BUHS), 125/1, Darus Salam, Mirpur, Dhaka-1216, Bangladesh; Tel: +88-02_8035502-3, +88-01715329039; E-mail: uttaron_007@yahoo.com complications which include dehydration, impaired renal function, acidosis, secondary infections and disseminated intravascular coagulation as well as hypotension and fainting [5]. The alarming situation is aggravated by delay in initiation of treatment and inadequate rehydration resulting in high morbidity. The importance of first five years of life of a child for its growth and development is well known. Any adverse influences operating on children during this period e.g., malnutrition and infection may result in severe limitations in their growth and development, some of which may be irreversible $[6,7]$.

Sometimes it imagines that diarrhea is an old and non-significant problem, but the reality is that diarrhea is still a very serious problem in developing countries. These diseases are more to be found in developing countries like Bangladesh where the population density, high urbanization and lack of clean water and sanitation provide suitable setting for the infectious diseases like diarrhoea to spread. Approximately 50,800 under-five children die every year due to diarrheal diseases in Bangladesh [8]. 
Mother's basic knowledge about diarrhea depends on various factors such as socio-demographic status and prior experience of managing the disease. Mother's education can cause behavioral changes that can be helpful in reducing diarrhea morbidity rates [9]. Many of the studies have not been able to explore the role of socio-economic characteristics with mother's knowledge in shaping or hindering the prevention of childhood diarrhea. This study therefore intended to determine the association between socio demographic attributes and mother's knowledge on childhood diarrhea.

\section{MATERIALS AND METHODS}

\section{Study Design}

It is a cross sectional analytic study which was carried out during a 6-month period using face to face interview guided by a structured questionnaire. The study was conducted in International Centre for Diarrheal Disease Research, Bangladesh (ICDDR,B), Dhaka, Bangladesh and it involved all mothers with under five years children. Purposive sampling technique was used during data collection, where a sample size of 170 was determined. Inclusion and exclusion criteria for participants were all willing and unwilling mothers of under five years children, respectively. The interviews were conducted at hospital settings by pre-trained researchers.

\section{Data Collection}

The main issues that were addressed were sociodemographic characteristics, frequency of diarrheal episodes among the children's and the mothers' knowledge on diarrhea. The questionnaire was then undertaken; to gather information about understandability, time consumed by each question, consistency among related variables and acceptability. After reviewing the questionnaire, changes were incorporated accordingly. Then the questionnaire was finalized after necessary modification.

\section{Data Analysis}

Data were cleaned, edited and verified daily to exclude any error or inconsistency before coding and entering them into a database. Mothers scored one point for each knowledge question answered correctly and they scored zero for wrong and do not know answers. Poor knowledge corresponded to a score of (<Mean - $1 \mathrm{SD}$ ); average knowledge corresponded to a score between (Mean $\pm 1 \mathrm{SD}$ ); good knowledge corresponded to a score of (>Mean +1 SD) [10]. Chi square was used to study the association between the socio-demographic characteristics of the mothers and their children's episodes of diarrhea and their knowledge and practices. Pearson correlation was used to determine the correlation between sociodemographic factors and maternal knowledge about diarrhea. The coded information was statistically analyzed for frequency, association and correlation using the Statistical Package for the Social Sciences (SPSS version 17) software. The statistical tests were considered significant at a level $p<0.05$.

\section{RESULTS}

The distribution of the socioeconomic and demographic characteristics of the respondents is shown in Table 1. The mean age of the respondents was $27(\mathrm{SD}= \pm 5.6)$ years. Service was the primary occupation (26.5\%) of the father followed by small business, labour, driver and others. Majority (46.5\%) of the mother's were educated up to primary level. The mean family income was $9818(\mathrm{SD}= \pm 3331)$ and forty seven percent of the respondents had average monthly income between 5001 and 10000 taka. In the case of accessibility to mass media, $20 \%, 75.9 \%$ and $87.6 \%$ were did not watch TV, listen radio and never read newspaper respectively. All interviewees agreed that their children have had diarrhea in their life-times. Occurring diarrhea in several times per day was higher among male children (57\%) than female but statistically no significant differences between male $87(54 \%)$ and female 74 (46\%) under-fives were observed with respect of diarrheal episodes $(P=N S)$ (Table 2). Among the subjects the proportions of the level of poor, average and good knowledge score were $23.5 \%$, $59.5 \%$ and $17 \%$ respectively (Figure 1 ). On bivariate analyses, socio-demographic characteristics such as age $(p<0.001)$, education $(p<0.001)$ and income $(p<0.043)$ were positively associated with mothers knowledge (Table 3). On Pearson's correlation knowledge was significantly associated with mothers age, $(r=0.658, p=0.001)$, education $(r=0.268, p=0.001)$ and income $(r=0.170, p=0.027)$ (Table 4).

\section{DISCUSSION}

The central aim of this study is to investigate the association between socio-economic status and knowledge regarding childhood diarrhea among mothers of under five children in Dhaka city. Generally, socio-demographic factors such as mother's education and occupation, husband's employment status and 
Table 1: Socio-Demographic Characteristics of the Respondents $(n=170)$

\begin{tabular}{|c|c|c|}
\hline Variable & Number & Percentage \\
\hline \multicolumn{3}{|l|}{ Age of the mothers (years) } \\
\hline $16-21$ & 25 & 14.7 \\
\hline $22-27$ & 63 & 37.1 \\
\hline $28-33$ & 56 & 32.9 \\
\hline $34-39$ & 26 & 15.3 \\
\hline$M e a n \pm S D$ & \multicolumn{2}{|c|}{$27 \pm 5.6$} \\
\hline \multicolumn{3}{|l|}{ Mothers education } \\
\hline Illiterate & 42 & 24.7 \\
\hline Primary & 79 & 46.5 \\
\hline SSC \& HSC & 40 & 23.5 \\
\hline Graduate \& above & 9 & 5.3 \\
\hline \multicolumn{3}{|l|}{ Husbands type of occupation } \\
\hline Service & 45 & 26.5 \\
\hline Labor & 30 & 17.6 \\
\hline Small business & 40 & 23.5 \\
\hline Driver & 33 & 19.4 \\
\hline Others & 22 & 12.9 \\
\hline \multicolumn{3}{|l|}{ Family income (Tk)/month } \\
\hline Up to 5000 & 16 & 9.0 \\
\hline $5001-10000$ & 79 & 47.0 \\
\hline$>10000$ & 75 & 44.0 \\
\hline Mean $\pm S D$ & \multicolumn{2}{|c|}{$9818 \pm 3331$} \\
\hline \multicolumn{3}{|l|}{ Access to mass media } \\
\hline \multicolumn{3}{|l|}{ Watching television } \\
\hline Yes & 136 & 80.0 \\
\hline No & 34 & 20.0 \\
\hline \multicolumn{3}{|l|}{ Listening radio } \\
\hline Yes & 41 & 24.1 \\
\hline No & 129 & 75.9 \\
\hline \multicolumn{3}{|l|}{ Reading newspaper } \\
\hline Yes & 21 & 12.4 \\
\hline No & 149 & 87.6 \\
\hline
\end{tabular}

Results are expressed as number (percentage) and mean \pm SD.

Table 2: Demographic Characteristics of the Study Population Categorized by Diarrheal Episodes Among the Children's $(n=170)$

\begin{tabular}{|c|c|c|c|c|}
\hline Variable & \multicolumn{4}{|c|}{ Frequency of diarrheal episodes } \\
\hline $16-21$ & $0(0.0)$ & $5(20.8)$ & $7(29.2)$ & $12(50.0)$ \\
\hline $22-27$ & $0(0.0)$ & $3(15.0)$ & $6(30.0)$ & $11(55.0)$ \\
\hline $34-39$ & $2(2.9)$ & $8(11.6)$ & $20(29.0)$ & $39(56.5)$ \\
\hline
\end{tabular}


(Table 2). Continued.

\begin{tabular}{|c|c|c|c|c|}
\hline \multirow[t]{2}{*}{ Variable } & \multicolumn{4}{|c|}{ Frequency of diarrheal episodes } \\
\hline & $\begin{array}{c}\text { 1-3 times/day } \\
\text { n (\%) }\end{array}$ & $\begin{array}{c}\text { 4-6 times/day } \\
\text { n (\%) }\end{array}$ & $\begin{array}{c}\text { 7-9 times/day } \\
\text { n (\%) }\end{array}$ & $\begin{array}{c}>9 \text { times/day } \\
n(\%)\end{array}$ \\
\hline \multicolumn{5}{|l|}{ Mothers education } \\
\hline Illiterate & $1(2.4)$ & $7(16.7)$ & $17(40.5)$ & $17(40.5)$ \\
\hline Primary & $1(1.3)$ & $11(13.9)$ & $25(31.6)$ & $42(53.2)$ \\
\hline SSC \& HSC & $1(2.5)$ & $6(15.0)$ & $9(22.5)$ & $24(60.0)$ \\
\hline Graduate \& above & $0(0.0)$ & $1(11.1)$ & $1(11.1)$ & $7(77.8)$ \\
\hline \multicolumn{5}{|l|}{ Gender of the child } \\
\hline Male & $3(3.2)$ & $12(12.6)$ & $26(27.4)$ & $54(56.8)$ \\
\hline Female & $0(0.0)$ & 13 (17.3) & $26(34.7)$ & $36(48.0)$ \\
\hline
\end{tabular}

Results are expressed as number (percentage), $x^{2}$-test were performed as test of significance, $p<0.05$ was taken as level of significance.

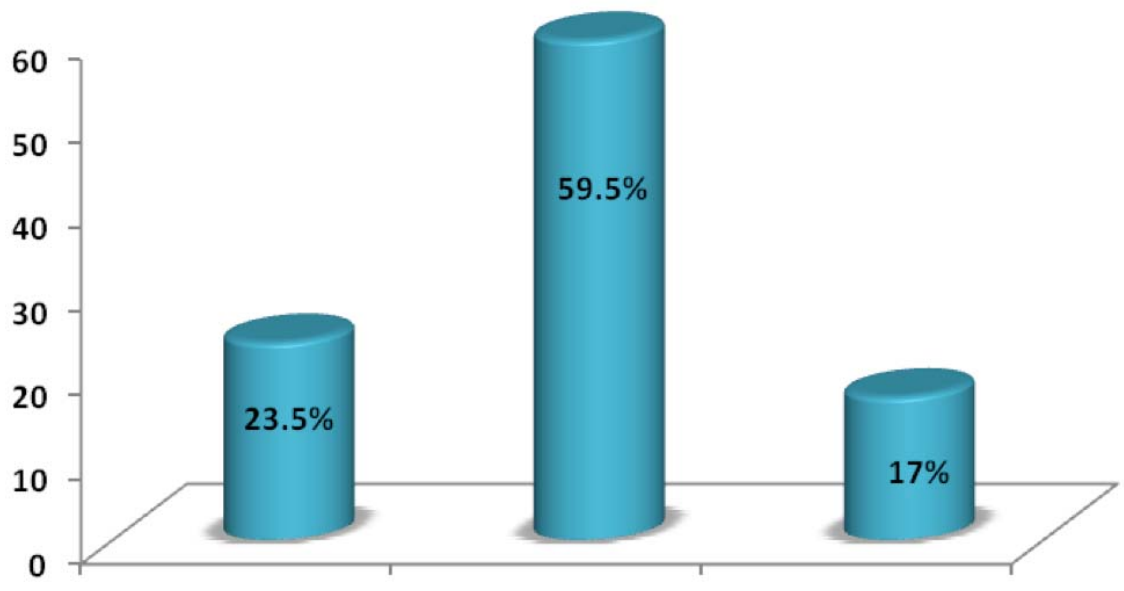

Poor Knowledge Average Knowledge Good Knowledge

Figure 1: Distribution of the level of knowledge among the respondents $(n=170)$.

Table 3: Association between Mother's Knowledge and other Related Demographic Variables $(n=170)$

\begin{tabular}{|c|c|c|c|c|}
\hline \multicolumn{4}{|l|}{ Age } & \multirow{3}{*}{0.001} \\
\hline $22-27$ & $10(50.0)$ & $7(35.0)$ & $3(15.0)$ & \\
\hline $28-33$ & $28(49.1)$ & $27(47.4)$ & $2(3.5)$ & \\
\hline Illiterate & $22(52.4)$ & $19(45.2)$ & $1(2.4)$ & \multirow[t]{4}{*}{0.001} \\
\hline Primary & $11(13.9)$ & $52(65.8)$ & $16(20.3)$ & \\
\hline SSC \& HSC & $6(15.0)$ & $22(55.0)$ & $12(30.0)$ & \\
\hline Graduate \& above & $1(11.1)$ & 8 (88.9) & $0(0.0)$ & \\
\hline
\end{tabular}


(Table 3). Continued.

\begin{tabular}{|c|c|c|c|c|}
\hline \multicolumn{5}{|l|}{ Access to media } \\
\hline Yes & $38(25.5)$ & $85(57.0)$ & $26(17.4)$ & \multirow[t]{2}{*}{ NS } \\
\hline No & $2(9.5)$ & $16(76.2)$ & $3(14.3)$ & \\
\hline No & $6(14.6)$ & $30(73.2)$ & $5(12.2)$ & NS \\
\hline \multicolumn{4}{|l|}{ Watch TV } & \multirow{3}{*}{ NS } \\
\hline Yes & $35(25.7)$ & $77(56.6)$ & $24(17.6)$ & \\
\hline No & $5(14.7)$ & $24(70.6)$ & $5(14.7)$ & \\
\hline
\end{tabular}

Results are expressed as number (percentage), $x^{2}$-test were performed as test of significance, $p<0.05$ was taken as level of significance, NS=Not Significant.

Table 4: Correlation of mothers Knowledge with Socio-Demographic Variables $(n=170)$

\begin{tabular}{|c|c|c|}
\hline \multicolumn{1}{|c|}{ Variables } & $\mathbf{2}$ \\
\cline { 2 - 3 } & $\mathbf{r}$ & $\mathbf{p}$ \\
\hline \hline Mothers age & 0.658 & $0.001^{* *}$ \\
\hline Mothers education & 0.268 & $0.001^{* *}$ \\
\hline Husband's monthly income & 0.170 & $0.027^{*}$ \\
\hline Frequency of diarrheal episode & -0.040 & NS \\
\hline
\end{tabular}

The level of significance at $p<0.05 ; r=$ correlation coefficient; NS=Not Significant.

family income are linked with mother's knowledge about diarrhea apart from mother's personal attitude and behaviour.

In developing countries, maternal education has been linked to the child morbidity and mortality [11]. The present study revealed that mother's knowledge about many aspects of diarrhea was grossly deficient particularly among younger and less educated mothers, which is in accordance with findings of studies in Riyadh and other regions of the country [12-14]. There seems to be a need for urgent corrective intervention to boost mother's knowledge about diarrhea since their role is pivotal for any preventive or control strategies.

Mean monthly income per household and years of maternal education was low in this study. Lower maternal education and socioeconomic status influenced on knowledge reported in a study from Mexico [15].

The diarrheal episodes in our study were more common in male children of less educated and young mothers with low family income. Similar findings were generally reported from studies in Saudi Arabia [12, 16$20]$ and in many other developing countries [3, 21-23].
In our study in total, $42 \%$ of the mothers had a good knowledge, while only $30 \%$ had average and $28 \%$ had poor knowledge regarding diarrhea. The mothers did not have adequate knowledge about diarrhea in this study. The knowledge of the mothers had significant relation with the age and education of the mother and father's monthly income. This low level of knowledge had been noted in other studies as well [24, 25].

The study also revealed that knowledge about diarrhea was negatively correlated with the episodes of diarrhea. In a study in Nigeria, the occurrence of diarrhea was significantly associated with the education of mother [26]. Although some studies revealed that the education of the mother was not related to the diarrhea management $[27,28]$, it seems that other factors such as the social class or family income might influence the mother's knowledge more than just their own education.

A study revealed that the mothers who received their information from media and personal reading had better knowledge [29]. But we did not find any significant association between mass media and mother's knowledge on diarrhea. Moreover, the research showed that media acts effectively in giving knowledge to the mothers. 


\section{CONCLUSIONS}

Mothers had inadequate knowledge about diarrhea and have found a strong relationship between sociodemographic attributes and mother's knowledge. There is a need of continuing health educational interventions for mothers having under five children to prevent diarrheal diseases.

\section{ACKNOWLEDGEMENTS}

Special thanks to the Bangladesh University of Health Sciences (BUHS), ICDDR,B and Prof. Liaquat Ali, Vice Chancellor, BUHS.

\section{REFERENCES}

[1] Van-den-Broeck J, Eekels R, Devlierger H. Child morbidity patterns in two tropical seasons and associated mortality rates. Int J Epidemiol 1993; 22: 1104-10. http://dx.doi.org/10.1093/ije/22.6.1104

[2] Muhe L, Byass P, Freij L, Sandstrom A, Wall S. A one-year community study of under-fives in rural Ethiopia: patterns of morbidity and public health risk. Public Health 1995; 109: 99109.

http://dx.doi.org/10.1016/S0033-3506(05)80003-4

[3] Waldman E, Barata C, de Moraes J, Guibu I, Timenesky C. Gastroenteritis and acute respiratory infections among children up to 5 years old in an area of Southeastern Brazil, 1986-1987, II-Diarrhea. Rev Saude Publica 1997; 31: 62-70.

[4] Walker A. Common health problems in Northern Territory aboriginal children. Aust Fam Physician 1994; 23: 55-62.

[5] Gabr M. Malnutrition and diarrhoeal disease. Diarrhoea Control Newsletter 1983; (1): 3-4.

[6] William B, Gouwse, Dye C. Estimate of Worldwide distribution of child deaths. Lancet 2002; 2: 25-32.

[7] Black R, Morris S, Bryce J. Where \& Why are 10 million children dying every year. Lancet 2003; 361: 2226-34. http://dx.doi.org/10.1016/S0140-6736(03)13779-8

[8] Diarrhoea: why children are still dying and what can be done: The United Nations Children's Fund (UNICEF/World Health Organization (WHO), 2009. Availablefrom: http://www.unicef. org/media/Final_Diarrhoea_Report_October_2009_final.

[9] Chakrabarti A. Determinants of Child Morbidity and Factors Governing Utilisation of Child Health Care: Evidence from Rural India. Working Paper 63/2012. December 2012.

[10] Priyanka Raj CK, Angadi MM. Hospital-based KAP study on diabetes in Bijapur, Karnataka. Indian J Med Special 2010; 1(2): 80-83.

[11] Berlin EA, Berlin B. Medical Ethnobiology of the Highland Maya of Chiapas, Mexico: The gastrointestinal diseases. Princeton, New Jersey: Princeton University Press 1996.

[12] Al Mazrou Y, Farid S. Saudi Arabia Child Health Survey, Kingdom of Saudi Arabia: Ministry of Health 1991; pp. 82-93.

[13] Rasheed P. Perception of diarrheal diseases among mothers and mothers-to-be: implications for health education in Saudi Arabia. Soc Sci Med 1993; 36: 373-77.

http://dx.doi.org/10.1016/0277-9536(93)90022-V
[14] Al-Jurayyan N, Al-Nasser M, Al-Rashed A, Al-Mugeiren M, Al-Mayzad A, Al-Eissa Y. Management of acute childhood diarrhea in Saudi arabia: practices versus WHO recommendations. East Afr Med J 1994; 71: 110-12.

[15] Hielscher S, Sommefeld J. Concepts of illness \& utilization of health care services in a rural Malian Village. Soc Sci Med 1985; 21(4): 469-81.

http://dx.doi.org/10.1016/0277-9536(85)90227-8

[16] Annual Health Report. Kingdom of Saudi Arabia: Ministry of Health 1998.

[17] Qadri M, Al-Ghamdi M, Musharaf A, Haq M. A study on diarrheal diseases in children under five years of age. Ann Saudi Med 1992; 12: 459-62.

[18] Al-Mazrou Y, Khan M, Aziz K, Farag M, Al-Jefry M. The role of social factors in the prevalence of diarrheal diseases in under-five Saudi children. J Trop Pediatr 1995; 41(Suppl 1): 45-52.

[19] Milaat W, Elassouli S. Epidemiology of diarrhea in two major cities in Saudi Arabia. J Commun Dis 1995; 27: 84-91.

[20] Khan M. Does hilly ecology prevent childhood diarrhea? Bangladesh Med J Res Counc Bull 1995; 21: 38-45.

[21] Vasquez M, Mosquera M, Cuevas L, Gonzales E, Veras I, Batista $M$, et al. Incidence and risk factors for diarrhea and acute respiratory infections in urban communities of Pernar Brazil. Cad Saude Publica 1999; 15: 163-71.

[22] Shamebo D, Sanstrom A, Muhe L, Freij L, Krantz I, Lonnber Wall S. The Butajira project in Ethiopia: a nested casereferer of under-five mortality and its public health determinants. Bull World Health Organ 1993; 71: 389-96.

[23] Rahmanifar A, Kirksey A, McCabe G, Galal O, Harrison G, Jerome N. Respiratory tract and diarrheal infections of breast-fed infants from birth to 6 months of age in household contexts of an Egyptian village. Eur J Clin Nutr 1996; 50: 655-62.

[24] Othero DM, Orago AS, Groenewegen T, Kaseje DO, Otengah PA. Home management of diarrhea among underfives in a rural community in Kenya: household perceptions and practices. East Afr J Public Health 2008; 5(3): $142-6$

[25] Shah MS, Ahmad A, Khalique N, Afzal S, Ansari MA, Khan Z. Homebased management of acute diarrhoeal disease in an urban slum of Aligarh, India. J Infect Dev Ctries 2012; 6(2): 137-42. http://dx.doi.org/10.3855/jidc. 1374

[26] Yilgwan CS, Okolo SN. Prevalence of diarrhea disease and risk factors in Jos University Teaching Hospital, Nigeria. Ann Afr Med 2012; 11(4): 217-21. http://dx.doi.org/10.4103/1596-3519.102852

[27] Mengistie B, Berhane Y, Worku A. Predictors of Oral Rehydration Therapy use among under-five children with diarrhea in Eastern Ethiopia: a community based case control study. BMC Public Health 2012; 12(1): 1029.

\section{http://dx.doi.org/10.1186/1471-2458-12-1029}

[28] Asakitikpi AE. Acute Diarrhoea: Mothers' Knowledge of ORT and Its Usage in Ibadan Metropolis, Nigeria. Ethno Med 2010; 4(2): 125-30.

[29] Ghasemi AA, Talebian A, Masoudi Alavi N, Mousavi GA Knowledge of Mothers in Management of Diarrhea in UnderFive Children, in Kashan, Iran. Nurs Midwifery Stud 2013; 1(3): 158-62.

http://dx.doi.org/10.5812/nms.10393 